\author{
Marquette University \\ e-Publications@Marquette
}

Social and Cultural Sciences Faculty Research and Publications

Social and Cultural Sciences, Department of

$12-15-2017$

\title{
Learning from Zũni War Gods Repatriating Alternative Dispute Resolution for Practice and Research
}

Alexandra Crampton

Marquette University, alexandra.crampton@marquette.edu

Follow this and additional works at: https://epublications.marquette.edu/socs_fac

Part of the Social and Behavioral Sciences Commons

\section{Recommended Citation}

Crampton, Alexandra, "Learning from Zũni War Gods Repatriating Alternative Dispute Resolution for Practice and Research" (2017). Social and Cultural Sciences Faculty Research and Publications. 231. https://epublications.marquette.edu/socs_fac/231 
Marquette University

e-Publications@Marquette

\title{
Social and Cultural Sciences Faculty Research and Publications/College of Arts and Sciences
}

This paper is NOT THE PUBLISHED VERSION; but the author's final, peer-reviewed manuscript. The published version may be accessed by following the link in the citation below.

Meditation Theory and Practice, Vol. 2, No. 2 (2017) : 131-156. DOI. This article is (C) Equinox Publishing and permission has been granted for this version to appear in e-Publications@Marquette. Equinox Publishing does not grant permission for this article to be further copied/distributed or hosted elsewhere without the express permission from Equinox Publishing.

\section{Learning from Zũni War Gods: Repatriating Alternative Dispute Resolution for Practice and Research}

\author{
Alexandra Crampton \\ Social and Cultural Sciences, Marquette University, Milwaukee, WI
}

This article applies lessons learned from the Zũni people of the southwestern United States about successful and sustainable intervention as a metaphor to address common tensions among alternative dispute resolution (ADR) scholars and practitioners. These tensions are found in professionalisation, institutionalisation and identification of best practices. Through example of Zũni efforts to repatriate sacred artefacts known as Ahuy: da, I argue that $A D R$ is an intervention that works best through direct and ongoing dialogue rather than rigid adherence to a set of standards. The problem lies in how such adherence can limit and distort rather than inform or support best practices in research as well as mediation practice. I propose qualitative, ethnographic field research as a way to address this problem, and provide an example from ongoing study of a US family court mediation programme.

Keywords: alternative dispute resolution, mediation; research, best practices, family law, court mediation 


\section{Introduction}

As a cultural anthropologist, I have been trained to deepen my understanding of social practices, such as alternative dispute resolution (ADR), through perspectives learned from different cultures. These perspectives have also improved my work as an ADR scholar. In this article, I present lessons learned from the Zũni people as a metaphor to think through common tensions among ADR scholars and practitioners about professional practice. These include challenges of professionalisation, institutionalisation and identification of best practices. Through negotiation with museum curators, the Zũni have been able to repatriate sacred artefacts so that these 'war gods' may better serve a goal of peace. I argue that ADR researchers and practitioners similarly should repatriate our models rather than try to identify and preserve a permanent 'best practice' model. I begin by explaining the repatriation metaphor in the context of mischief that can come through failing to allow model flexibility in research and practice.

\section{Repatriation and deterioration that bring peace to local landscapes}

The Zũni people have lived in what is now the southwestern part of the United States for centuries. Each year, members of Deer and Bear clans carve twin 'war gods' (or Ahuy: da), which are 'deities of great power' that also, 'serve as protectors' in times of war and peace (Ferguson, An yon and Ladd 2000:251). They are placed in the landscape to ensure balance, and work by slowly becoming part of that landscape through deterioration (Merenstein 1992). They are communal property that should never be removed (Suro 1990:A13).

In the nineteenth century, the US government hired anthropologists to collect Native American cultural practices and objects for preservation in what became the Smithsonian Institution in Washington, DC. The presumption was that the value of cultures could be captured, catalogued and made permanent through scientific storage and display. As with other natural artefacts, the wood and feathers of Ziini war gods were saturated with chemicals to ensure preservation (Johnson 2001). This has been the Western practice for knowledge development and progress. What we academic types value is analysed scientifically, labelled and placed under glass. In this technical-rational approach, complex and dynamic social practices are reduced to static models that are then evaluated using standard measures. This risks oversimplifying, distorting or even destroying understanding of what these artefacts mean to native peoples outside of artificially controlled settings. In this article, I refer to scientifically and professionally controlled knowledge development, preservation and dissemination as the museum model of direct, lived experience.

Since the 1970s, the Zũnis have successfully negotiated for the return of sacred and cultural artefacts from the Smithsonian and other collectors. The Zũni were particularly concerned about Ahuy: da because removal had led them to cause mischief such that they were 'wreaking havoc with the natural environment' (Merenstein 1992). This included 'military conflicts, fires, earthquakes, floods, tornados, hurricanes and other violent occurrences' (quoted in Merenstein 1992:590). As the tribe's lieutenant governor told the New York Times in 1990, 'They can play little tricks and can do destructive things, especially when they are taken from their proper places ... there is one in California that maybe has done some earthquakes there' (Lasiloo quoted in Suro 1990:A13). Return was essential not only to right the wrongs of US government policy but also to restore peace in the natural and human landscape. One complication moving forward was how chemical preservation of these Ahuy: $d a$ threatened ability to perform this function once put back in place. Repatriation from climate controlled museum object to peaceful intervention would not be automatic or easy.

As part of the US history of knowledge development, the Zũni war god repatriation storey is a warning about misappropriation, misuse and misunderstanding. As a metaphor, I find it can also be useful in reflecting on ADR as an intervention to help others across the human landscape of social experience. I am less interested in finding the best museum version that captures ADR as it should be than in understanding how it works in the real world. There are ways in which modelling realities and standardising approaches erodes the intangible, intuitive and 
context-dependent dynamics of ADR in favour of a more scientifically validated and yet constrained representation of ADR practices. Using the Zũni war god storey, we can see the danger of going too far and ending up too far removed from the real-life contexts that inspire us. And, we can see a shared concern that ADR as represented scientifically or technically may not fully represent the full range of ADR expert work in actual cases. Or, what social scientists also refer to as 'in the field' of lived experience.

Using the metaphor, these concerns are about mischief that prevents realisation of intervention benefits. Repatriation as a solution would allow these models to 'dissolve' through active engagement by all participants (and research observers).

An important difference between Ahuy: $d a$ and $A D R$, of course, is that ADR as intervention is not a living god, and is made real through human interaction and collaboration. While the Ahuy: da were stolen and had no place in museum work,ADR would not have materialised as a specialised area of practice without some isolation, objectification and preservation through scientific study and professionalisation. Within professional culture, the museum-type work of naming, categorising and displaying ADR as knowledge artefact has made ADR into an easily recognised and valued intervention. And, the preservation work of standardisation is used as protection against human fallibility. The intention, at least, is that fewer people will use ADR inappropriately or ineffectively by following and being held accountable to best practice models. At the same time, the war god metaphor provides cautionary tales of focusing too much on what can be identified and measured using technical-rational approaches at the expense of keeping the dynamic, intuitive and more intangible aspects of ADR alive. As a metaphor to address gaps between research and practice, the dangers of chemical preservation in museum work may be analogous to research protocol controls necessary for statistical validation that do not allow sufficient flexibility to understand how museum models really work once outside research studies and released into the field. There is a continuing need to allow ADR intervention models to essentially dissolve in the process of transforming difficult negotiations and conflict both in practice and in conducting research on that practice. I advocate repatriation of ADR in the sense of allowing greater dialogue and collaboration between museum modelling and direct practice work in which one way of conceptualising, analysing, or validating ADR is not privileged over the other. In this approach, ADR should be studied not only for how it may transform and improve but also how it may be transformed or even disappear through direct engagement and actual practice. The challenge is not in choosing the best museum model or the best of lived experience but rather how to maintain a productive exchange and dialogue between museum and field based work. This next section provides more specific application to challenges of ADR professionalisation, institutionalisation and identification of best practices.

\section{The promise and perils of professionalization}

The museum work of nineteenth and twentieth century anthropologists is analogous to the cultural practice of professional legitimation used by ADR professionals. Field based, real world examples formed the basis for distilling models used to analyse negotiation and conflict, as well as to identify best practices for how to intervene (and also in teaching negotiation, see Patton 1984). Clear labelling and instructions have helped educate the public on what ADR is and how it is used, as well as in training new professionals. Objectification and standardisation are necessary processes for distinguishing ADR from other forms of intervention, for marketing services and for establishing quality control. Museum models of ADR provide standards to which funded programmes can be held accountable, and to identify ADR practitioners who are not engaging ethically, effectively or professionally (Dingwall and Kidd 2003). Standard evaluation measures provide ease of comparison across programmes and application contexts, which in turn helps to solidify the concept of ADR as a professional specialty. As a distinct specialty, ADR has travelled widely through such diverse settings as playground, boardroom, court and international conflict (Coben 2006). The scale and scope of ADR today would 
have been hard to achieve without museum models of what this looks like and how to evaluate what it means. Settlement or agreement rate has been the dominant measure of mediation museum model success.

At the same time, professionalisation can create problems. Those who have advocated for ADR as a social movement in particular may find that a museum audience is too far from the field for productive engagement (Coy and Hedeen 2005). Like the paying visitors and donors of museum work, policymakers or institutional funders may in fact cause mission drift in order to see the results they want rather than what is best for transforming conflict in the field. Another kind of mischief is tension between ADR as more of an art than a science; as more nuanced and context dependent than can be captured and modelled (Mayer 2013). Overly rigid application outside museum walls of manuals and brochures can be misleading at best and is the mark of a novice rather than expert.

One answer to this dilemma is to maintain dialogue between museum curators maintaining professional standards and field based experts. We do this as a matter of professional practice by inviting practitioners to scholarly conferences and vice versa. Another dialogue of importance is between what is called frontline and management work in social work. That is, ongoing dialogue between ADR practitioners in the field and the directors or managers of programmes. For example, the Milwaukee family court mediation programme has done several things to encourage dialogue and collaboration between court based legal professionals and mediators. One is a manual based on collaboration among mediators, judges and other legal professionals, mental health professionals, and mediation programme staff. The manual project was started during an ADR conference sponsored by the Marquette Law School in 2009 (Schneider 2012). The manual is used to maintain programme standards and orient new mediators to programme expectations. Ongoing dialogue is maintained through a bi-monthly roundtable at which mediators discuss cases for which the manual may not have all the answers, and which sometimes lead to greater elaboration through an annual training sponsored by the court.

\section{Co-optation by powerful institutions}

Museums were created to preserve and protect valuable knowledge and artefacts. When Ziini leaders negotiated repatriation, they were selective such that some items remained in museums and private collections (Ferguson, Anyon and Ladd 2000). ADR is of course different because it has not survived as intended outside of some institutional support. Grassroots and community-based pilot projects have largely faded, and some have only survived through contracts with formal institutions, such as schools, businesses, government and courts (Dingwall and Kidd 2003 ). For example, I learned from a research respondent in 2004 that one of the Neighborhood Justice Centers funded in the 1970s eventually changed its name to the Justice Center because it primarily serves people through the courts in Atlanta.

Institutionalisation allows preservation but at what cost? This has been much debated within court annexed and court based mediation programmes (Alfini, Barkai, Bush, Hermann, Hyman, Kovach, Liebman, Press and Riskin 1994). ADR critics argue that party self-determination is undermined through imposition of state interests through the law. One problem is that final case resolution has to fit legal parameters in defining problems and solutions. Another is how state interests in social control are implemented through application of law, and how attorneys (barristers in the UK) may steer cases in order to win. A practical concern is how mediation as a court intervention can change when courts cut programme funding to help reduce costs (Dingwall 2010; Merry 1990; Silbey 1993; McAdoo and Welsh 2004).

One response to such mischief is to wrestle autonomy back from courts. In Australia, mediation has moved from family court to family service centres physically located outside courthouses in order to bring greater separation (Moloney, Qu, Weston and Hand 2013; Parkinson 2014). In a sense, this might repatriate ADR back to the community - albeit through a different set of professionals. Others argue for need to examine ADR as simply different when part of the law and court system. Nancy Welsh argues that court based mediation is in an 'ugly 
duckling phase' (Welsh 2011:876) in which ADR integration has been messy and uneven across court contexts. The goal might not be removal of mediation from court but rather to understand how mediation changes as it becomes part of court contexts, and to evaluate repatriation options from this analysis.

A third response is to find value within constraints. Dingwall and Kidd (2003) argue that some degree of cooptation - or 'isomorphism' - is a necessary price for the benefits of institutionalisation, such as court referrals. In fact, unintended outcomes can also have a positive impact on court case resolution. Family court attorneys in the US find that bargaining in the shadow of the law, with the pressure of court involvement, provides necessary reality checks on their clients (McAdoo and Welsh 2004). Trinder and Kellett (2007:332) found in England that family court mediation has become part of the 'paradoxical assistance' of courts. That is, some parents found the court based ADR so unhelpful that they began to resolve problems on their own. A key mediation goal of party self-determination may thus be realised despite failing to reach agreement during the mediation itself. Failure can paradoxically also bring a degree of success.

\section{ADR practice reductions through research}

Museum curators continually make decisions about how to accurately represent complex behaviours, interactions and other forms of lived experience for museum displays. Just as choices must be made in what and how to display artefacts in a museum, choices must be made in models of practice about how to frame and what to include as significant factors. It may not be possible nor desirable to include every nuance, factor or dimension for the sake of coherence and clarity. This tension in ADR is seen in debate over how to best articulate best practice standards without being able to fully explore the range of mediation practices and practice model modifications that have been developing in the field. Once again, this is analogous to past problems in museum work. Historically, some of the decisions made by the Smithsonian for museum displays became the categories used for scientific study (Adams 1998). For example, Native American artefacts were divided such that displays of basket weaving were kept separate from pottery making. Only many years later were first nation people better consulted about whether these distinctions were meaningful to them. In terms of ADR, I have attended conferences in which practitioners complained that academics were speaking in stereotypes rather than accurately representing the full range of mediation as found in the field (Crampton 2006).

ADR researchers can follow the practice of anthropologists who now spend much more time checking models learned from academic literature with the people living in their field sites. In application to ADR research, this means consulting with mediation professionals, professionals whose work is impacted by mediation (such as family court judges and attorneys) and disputants. Such field research is especially important today given how long mediation has been practiced 'in the wild' and potentially far from expert practice. And, it requires attention to more than the outcomes that professionals may expect to see. For example, mediation benefits are often marketed in terms of how mediation experts fix problems. While this construction is necessary for competition with other problem solving options (such as courts), it implies a one-way direction of exchange through transfer of knowledge and practice from the expert to the disputant (or consumer). This is one possibility. Another is failure in making the same attempt. Yet more possibilities emerge when the intended intervention is perceived and responded to by participants in ways that best practice models do not anticipate. As will be seen from practice examples presented in this article, standard evaluation measures may inadequately assess intervention success.

Of course, it can be hard to translate all nuances and complexities of everyday practices into research models. There is often an art to the science of ADR that is difficult to capture. One option is to repatriate research design and methods to field based realities. For example, field based scholars use research approaches that start with field experience rather than practice models. These are studies of what Karen Staller calls, 'practice based 
evidence' (Staller 2006). Donald Schon explains this in terms of rejecting technical rationality and espoused theories as accurate explanations for what experts actually do in the field (Redmond 2004). He studied the latter through focus on 'reflection-in-practice' as experts both draw from previous models and adapt as needed (Schon 1983). Elizabeth Stokoe uses examples of actual rather than modelled practice to identify best practices and to teach professionals how to improve their craft (Stokoe 20I I).

My approach to bridging research and practice as a cultural anthropologist is through ethnographic field work. Although this method has been used in past mediation studies (see Simpson 1998; Merry 1990), the following section re-introduces ethnography given how infrequently this method is currently used.

\section{Ethnography}

Ethnography is hard to define but entails trying to study social phenomena, such as culture, conflict, or intervention, as fully and holistically as possible. What may be important to the researcher, for example, may be inconsequential or simply different for what matters to those directly engaged in what we study. Although research topics and questions begin in literature stored within ivory tower literature of the discipline, the benefit and accuracy of findings requires that these models of reality dissolve as necessary once studied in the field. In studies of culture, critique by research subjects (and those who became 'native anthropologists') have changed how scholars define cultures, and this in turn has changed research protocols to become more flexible. For example, anthropologists today will more tentatively predefine the boundaries of field sites and what variables to study so that research subjects may challenge and change the direction and interpretations of research. Otherwise, academics are merely using our museum models to talk to ourselves through data that happened to have been collected in a field-based context. The principal research method in ethnography has been characterised as 'hanging out' to emphasise the necessity of learning through experience (Bernard 2002). The more technical term is participant observation, in which researchers participate directly as much as possible and observe for later recording and reflection. The researcher becomes the principle research instrument rather than a standard survey or set of data collection tasks. Given past errors of ethnocentric interpretations, much time is spent on 'reflexivity', which entails the action and reflection of a reflective practitioner as well as ongoing dialogue with those in the field site (interlocutors) and with academic experts through conferences and reading literature (Burawoy 2003).

Of course, no research design or method is without limitations. Ethnographic research is far messier than the controlled settings of other approaches, such as those conducted in a research lab. There are unique risks to quality in field research data collection. For example, participant observation requires developing rapport over time to ensure candid responses, and this process can become highly personal. Anthropologists can use personal connexion to manipulate or coerce responses. They can also be manipulated themselves, and co-opted by people they study. This is due to blurring of boundaries in an effort to remove artificial barriers to communication and canned responses. There are, therefore, risks along with the potential rewards to using highly personal approaches that allow candid exchange. Taking periodic breaks from the field allows greater reflection whether research boundaries have been sufficient for accurate and ethical data collection.

In my ongoing family court mediation study, ethnography has been integrated with a standard mediation evaluation research design. By standard evaluation design, I refer to the familiar ADR industry standard in which the mediation case or case sessions are the unit of analysis. I call this the museum model for evaluation research. It is a comparative case study design in which ADR is conceptualised as an intervention that either works to produce desired outcomes or does not. The preferred comparison is between randomly assigned control and experimental groups through randomised control trials (RCT). The next best comparison is the pre/post research design; comparing time two, post intervention, with time one, pre-intervention. This quantitative research design was instrumental in developing professional standards for evaluation, such as 
mediation agreement. Out of these standard research practices has come the evidence used to explain how and why mediation works.

Thus, inclusion of a standard mediation evaluation research design was necessary for my study. However, I added ethnographic extended case study methods to better understand changes in how mediation works currently given how court and private family contexts have changed. This is the repatriation portion of the study. Fields of inquiry were opened up beyond mediation cases, case sessions and mediation programmes. This entailed immersion in the institutional and social contexts in which mediation cases are referred, conducted, and then impact private family lives. When formal interviews were conducted, I used a semi-structured approach in which participants are asked a few standard questions but also encouraged to then lead the conversation according to what mattered to them. This helped collect data outside professional presumptions of how mediation works and to what purpose by allowing participants to define what is of importance and then how mediation fits (or conflicts) within their priorities and perspectives. The next section provides more detail in research study design, data collection and implications for understanding mediation practice.

\section{Child custody mediation in a US family court}

Child custody mediation in the US was first developed as a family court intervention to help marital reconciliation, and then became more integral starting in the $1980 \mathrm{~s}$ as a way to facilitate a more amicable divorce (Saposnek 2004). In the US, custody cases include 'custody' as legal responsibility for such decisions as health care, education and religion, and 'placement', which refers to child residence. An experimental pilot study by Bob Emery and colleagues provided empirical evidence that mediation helped reduce costs, reach settlement on custody and placement, and allow both parents to continue contact with children post-divorce (Emery 2012). This research and similar studies led to a museum model of child custody mediation in which mediation is a distinct alternative from litigation that leads to a better divorce settlement. Presumed case characteristics include a nuclear family with no additional children or partners, attorney representation and a marriage that lasted long enough for a substantial intimate partnership to have been formed. In my research, I have found that mediation trainings continue to use this type of case as a standard from which other types of cases are then contrasted as examples of special issues. Success is primarily evaluated through calculating agreement rates.

This made sense twenty to thirty years ago when mediation was pioneered as a way to reduce the adversarial dynamics of divorce as a one-time event (Press 2013). In particular, mediation was intended to help bring a 'good divorce' (Amato, Kane and James 2011:511) in which parents could separate property and private lives while maintaining a relationship for the sake of children (in legal terms, the 'best interests of the child') as coparents. A 'tender years' presumption in courts meant that mothers typically were awarded full custody and primary placement such that co-parenting was limited to coordination of the father's time for vacations and/or alternative weekends (Fineman 1991).

Today, the nuclear family divorce settlement is another museum model that inadequately reflects the full landscape of family court caseloads given changes in law and society. These changes include the impact of legal reform towards greater gender equality, a father's rights movement pushing for more parenting time and shared responsibility, and welfare reform that places greater responsibility on fathers. The resulting ideal 'good divorce' outcome is one of shared parenting rather than primary parenting by the mother. This means that parenting is more than a one-time agreement. Instead, previously married and cohabiting partners must continually negotiate and collaborate post judgment. Meanwhile, never married parents may not have had a significant prior relationship. In these cases, co-parenting originates within court case negotiation, often initiated by Child Support Enforcement (to establish paternity). As a court official described of this post-court parenting, 'We make new families.' 
Overall, this expands the range of cases and raises the bar on what a long-term agreement is intended to achieve. At the same time, scholars have noted that court resources have declined since the days of mediation pilot studies (Salem 2009; Singer 2008). In addition, current caseloads bring complicating factors that were not part of (or under addressed) in previous studies (Ballard, Holtzworth-Munroe, Applegate and D'Onofrio 2011; Murphy and Singer 2015; Salem 2009). One is that court cases today are likely to include pro se parties who have not hired attorneys. Another complication comes when parents have children from previous relationships and/or new partners (Salem 2009; Murphy and Singer 2015 ). An ongoing concern identified through earlier research is domestic violence (Grillo 1991; Greatbatch and Dingwall 1999), substance abuse and other types of 'hard living' (Merry 1990). Less well discussed in the literature is the impact of a decline in real income across most social classes in the United States that has continued since the 1970s, and accelerated for some through the 2008 recession. This is significant in part due to the intertwining of parenting and money through most US state laws. In Wisconsin, child support payments are calculated in relation to placement schedules and parent income.

While professionals debate the significance of these changes on mediation process and outcome, empirical research has not kept pace (Saposnek 2004; Ballard, Holtzworth-Munroe, Applegate and D'Onofrio 20n). The purpose of my study is to repatriate the family court mediation model within the complex case factors of a family court mediation programme. This includes examination of the larger social and cultural contexts of who is considered family, what being a family means, and what ideals of family and parenting may be changing. The main research question in my study is not as much whether mediation still works but rather to examine how mediation works in real-life practice. Study background, methods and outcomes are next described to show how this has unfolded as well as results.

\section{Research setting}

The study focuses on a family court mediation programme for Milwaukee County in Wisconsin. In Wisconsin, as in most US states, mediation is mandatory for parents who file disputes over child custody or placement. In this programme, parents referred to mediation must attend an evaluation session before they are asked if they agree to continue to mediation sessions. The evaluation session fulfils the legal mandate and provides an opportunity to screen for domestic violence or substance abuse issues that make mediation inappropriate. Parents who agree to mediation pay a one-time fee of $\$ 200$ that can be waived. If mediation fails or is otherwise terminated, a guardian ad litem (GAL) is appointed to investigate and make a recommendation to the court. The majority of case filings are 'PA' or paternity cases in which parents have not married and the first step is determination of paternity. 'FA' or family cases include never married parents with paternity acknowledgement, divorce cases and post-judgment divorce cases. Each year, there are about 800 cases referred to mediation by court commissioners, judges, attorneys or by parent request. The PA cases outnumber FA cases. The programme agreement rate calculated each year is about 50 per cent. For example, in 2012 (the bulk of cases in my sample), there were 874 referrals to the mediation programme. Of those cases, 386 were mediated, and of those mediated cases, 191 reached agreement. The 191 number includes 42 cases in which parents reported that they reached agreement after court referral and/or evaluation session and before mediation sessions.

\section{Research design and data collection}

As previously mentioned, the study began as a standard evaluation project using mediation cases as the unit of analysis. The programme is run by court staff. The study sample consists of forty-two mediation cases by ten mediators (with sixty mediation sessions) that were referred through the court process between 20n and 2015. Each was observed directly and all but three were audio-recorded. The majority of mediation case data collection was in 2012. There are thirty-one FA cases and eleven PA cases, which means there is an over sampling of FA cases given the average mediation programme caseload. The FA cases include fourteen first time 
divorces (3 $3 \%$ of study sample), twelve post-judgment divorce cases (29\%), and five non-marital cases (combined with the PA cases, non-marital cases are $38 \%$ of the sample). The sample agreement rate (54.7\%) uses the mediation programme standard for identifying agreement, which is a written agreement signed by all parties and submitted by the mediator. The study sample agreement rate is comparable to the mediation programme agreement rate as a whole.

The study sample is a convenience sample given data collection challenges. That is, this research requires multiple research permissions (from the court, mediators and parents) in order to observe mediation cases. Requesting research consent becomes an ongoing process through application of an extended case study approach. Following cases includes tracking cancellations and rescheduling over extended periods of time. Study sample cases were collected through attending (and observing as part of data collection) the mandatory, premediation evaluation sessions held at the courthouse. In addition, six mediators notified me of their upcoming mediations. Parent consent to study participation, therefore, was either conducted just prior to an evaluation session or to mediation (or both, in terms of re-consent). Mediators typically conducted mediations in rented office space.

Semi-structured interviews were used to supplement data collection through direct observation, and to test my ongoing analysis. They were conducted after evaluation sessions (for those parents who never mediated) and after mediation sessions. In the mediator sample are the ten observed mediators and six of the additional twenty mediators who were observed only during evaluation sessions. In the parent sample are fifteen pairs of parents, one half of a parent pair interviewed after mediation, and five parents interviewed after the evaluation session. Mediators were interviewed in their offices or more informally in coffee shops. Parents were asked to identify whether they preferred to be interviewed at home, at work or at my university (Marquette University). Interview by telephone was also an option. Chosen locations included homes, workplaces, a coffee shop and the university library conference room. Two parents consented to interviews by telephone only. Ethics oversight for treatment of human subjects was reviewed by the Marquette University Institutional Review Board, which also required a formal letter of consent to allow research by the chief justice of the court. Parents were paid $\$ 30$ per interview, and research subjects were otherwise not paid.

In standard mediation evaluation research design, mediation cases or case sessions are the unit of analysis. This mirrors the perspective of mediation professionals, who meet parents at the evaluation session ( or mediation if the evaluation session is waived) and never see them after the case is closed. There are at least two additional perspectives that are not adequately considered using this approach. One is how mediation is embedded within family court and the other is how mediation and family court are embedded within the daily lives of parents who may or may not be interested and able to co-parent amicably. While it has not been logistically possible to follow cases closely through court and daily lives on an ongoing basis, more modest data collection was added through extended ethnographic case study methods. In particular, mediation cases were followed beyond individual mediation sessions as they were embedded within a process of court filings, hearings and either final orders or case dismissal. Court record examination facilitated this process. I also immersed myself within mediation programme contexts, which allowed informal interviews during these processes (as appropriate). In this study, contexts include a forty-hour mediator training commonly used to qualify for the court roster, mediation programme annual trainings and monthly 'roundtable' debriefings, court based procedures, mediation evaluation sessions and mediation sessions.

As I became a more familiar part of the court and mediation programme contexts, I introduced myself and requested permission for observation and to talk with those unfamiliar with the project, and periodically reminded people of my role as a researcher. Special attention to individual research permission had to be requested of those observed during evaluation sessions, mediation sessions and individual interviews. An informal, verbal consent protocol was used for evaluation sessions, and required consent by all present. A 
formal, written consent protocol was used for permission to observe and audio-record mediation sessions as well as conduct individual, audio-recorded interviews. In most cases, parents who agreed to mediation observation were willing if not eager to talk more following mediation. In two cases, interviewees commented that the interview had been more helpful than the mediation. In two cases, parents initially declined interviews and later agreed. Perhaps it took time to develop familiarity and trust. For example, when I walked into a mediator's waiting room for a new round of mediation sessions, a parent recognised me and said simply, 'Now, I will talk to you.'

Interviews with parents began in asking for prior experience of and knowledge about mediation. Most clearly understood the purpose and process of mediation as professionals try to convey. A common response was to generally agree with this purpose and a legal presumption of shared parenting. However, this was often followed with 'But in my case ... '. Given the open-ended flexibility of the interview, parents would then use the rest of the time to elaborate on personal complications. These elaborations led to potentially sensitive data collection because parents have shared thoughts and interests post mediation that had not been shared during sessions. Sensitive data collection also came through candid reactions to parents shared privately by professionals following court hearings and mediations. Family is rarely a neutral part of conversation. Both parents and professionals brought passionate memories and opinions into formal interactions and private understandings. Over time, it has become clear that strong emotional responses are an integral part of data collection as well as an ongoing research challenge (Crampton 2015).

\section{Results}

An important study result is finding mischief in presuming that signed mediation agreements are a clear evaluation measure of success. This measure may better reflect professional interests in clear standards; written agreement provides a simple metric for court staff to record and then provide to the court. These numbers, in turn, are used to justify continued funding and are sometimes used in calculating court savings through case diversion to private negotiation. However, this measure also misses the full complexity and messiness that parents include as they evaluate mediation in their cases. How can we know if agreement means success and termination means failure for the parents? What do they have to say when they are asked informally and through formal interviews to comment on their experience and the impact of mediation on what matters to them? In the study sample results, there are cases in which mediation ended in agreement and both parents attributed success in part to the mediation process in ways that mirror professional understanding. There are also cases that ended with termination in which parents attributed failure in part to the mediator or to the lack of decision- making authority on the part of the mediator, as also found in the literature. And then there are cases that are more confusing and complex. Closer examination reveals that agreement itself is hard to track in twelve out of forty-two cases. Data used for this examination comes from ongoing request for parent feedback while waiting for court hearings in the courthouse, and through semi-structured interviews with mediators and parents. In general, for parents, mediation was a small part of a larger court process that was ultimately interpreted through impact on personal lives as a parent, an ex-partner (or new partner in some PA cases), and in trying to raise a family. Thus, while mediators typically knew parents only within the confines of the mediation programme, parents interpreted mediation within a much wider lens of personal concern. This is now further detailed using case examples.

\section{Repeat players in court and need to expand the scope of 'family'}

In the museum model of family court mediation research, each mediation case is separate. Follow up is limited to whether agreements from a particular mediation are upheld over time. Parents are presumed to have had no prior experience with mediation and limited contact with court. However, in the study sample, there are repeat users of court and repeat referrals to the mediation programme over time. This is possible because case filing 
over custody or dispute over one child can potentially take place over eighteen years. As learned from court staff during research, the court is required to keep court files for thirty-nine years. As the court staff officer said, 'family cases never die'. The oldest case in the study sample was originally filed in 2000 . One mediator uses the term 'frequent flyers' for parents who have filed disputes over their children multiple times. Repeat users may also be parents who have children with different partners and ex-partners. For example, there is a case in which the mother has had three children from three different relationships, and was referred to mediation about conflict with the middle child and her ex-husband, who also has children from a previous marriage. In her interview, the mother complained of the cumbersome process to negotiate with each father individually given the more complex problem she has in raising her family. Yet, mediators are commonly trained to ask parents to focus on the present needs and future goals concerning the children of a particular case rather than an entire blended/ non-nuclear family. Data collected only from these mediation sessions may not capture these details that are nevertheless influencing what disputants are thinking, including what they might presume based on prior court and court mediation experience.

\section{Multiple mediations suggest need to take a longer view in evaluating success}

Mediation research typically analyses each case in isolation. However, the study sample includes cases referred to mediation more than once over time. And, mediation may work and then not work, or vice versa. This change over time becomes part of the cumulative mediation experience of parent disputants. For example, there is a case in which court mediation failed the first time, and then succeeded the second with a different mediator. The first mediator was probably never informed of the outcome because mediators rarely know the follow up to cases. The mediator in the second mediation reported that the parents were amicable and the case was resolved within one session. The proposed placement schedule in each mediation case was a continuation of what was already in effect. Therefore, it seems likely that there was a change in context that helped reach agreement rather than a particular mediator or mediation model. Mediation as intervention failed and then worked over time.

\section{Mediation termination and agreement within the vicissitudes of divorce}

In museum model research, signed agreements are a measure of mediation success. However, for parents, mediation termination or agreement may be rendered temporary over time as the case moves through court, and as they have to enforce agreements through compliance over time. In these cases, the change can be something internal to the parent and the vicissitudes of the conflict (particularly for first time divorces) rather than an objective change of circumstance. In one case, the parents first met the mediator through the courthouse evaluation, then were interviewed separately by the mediator, and then met for a four-hour session that ended in agreement. However, the father withdrew his agreement within two days. The mediation was recorded as a termination. Over time, the parents came back to mediation and signed an agreement. However, that mediation was conducted privately, and so is not part of the court record. The father later explained in an interview that he had not realised until the mediation session that a placement schedule would include when he would never see his kids. Despite having hired an attorney, attended the mediation orientation/evaluation and met privately with the mediator, this reality check did not hit him until he began working on an actual schedule. Prior to this, he had apparently been focused on placement as a schedule of when he would spend time with his children rather than time when he would not. He said he simply had needed time to understand and accept this, and also expressed great interest in avoiding a GAL appointment. In other words, 'the shadow of the law' (Mnookin and Kornhauser 1979) was also a factor in the eventual agreement.

\section{Domestic violence dynamics may vary or be variably identified}

Whether cases can and should be mediated given domestic violence history is of course debated in the literature. Another complication is whether domestic violence has taken place, and to what effect. Such 
assessment can change over time. For example, in one study sample case, the parents were so amicable that they teased the mediator for having posted a list of ground rules. 'Is that really necessary?' they asked. However, the follow-up mediation session never took place due to a domestic violence incident reported to the police. The case was later dropped. The father was eager at this point to be interviewed, telling me, 'I didn't do it but you probably get that all the time.' The mother declined an interview at that time. The court record shows that after mediation was terminated, there was a later suspension of the divorce itself. The parties were trying to reconcile. One attorney requested a copy of a draft agreement that had come from the first session in case reconciliation failed. Reconciliation eventually did fail, and the mediated agreement was used in negotiations for the final marital settlement agreement. The day of the divorce, the mother consented to be interviewed informally while waiting for the divorce hearing. She complained that opening a domestic violence case had only reduced help from the father in parenting (during the time of the restraining order), and added $\$ 2600$ in attorney fees. She described the incident from her perspective, and added that there would always be disagreement about what had happened. She said that they loved each other but could not get along. Both parents that day suggested that the court should offer counselling to help save marriages. How is court mediation assessed in this case? Was mediation a failure due to termination? Or, does the integration of preliminary agreement with the final court order (the marital settlement) indicate at least a partial success?

Another case provides an example of variable professional assessment regarding domestic violence and mediation. As a consequence, mediation agreement as success measure also changed. The parents had already been divorced. Prior to mediation, the mediator followed the courthouse evaluation session protocol. That is, the mediator met with each party after they had filled out a domestic violence and substance abuse screening tool. After receiving positive responses in a private review of this form with each parent, the mediator brought the two together. The mediator explained the mediation process, answered questions and provided an agreement to mediate form to sign. The form was signed and an initial session scheduled.

After three amicable sessions, there was a signed agreement. In post mediation interviews, both parents spoke positively of their mediation experience. They praised the mediator in contrast to past mediation experience they had had during the divorce. However, two years later after that amicable mediation agreement, I learned they were back in court. New professionals had been assigned to the case. One was a GAL and another was a social worker. There followed a court trial to settle the custody dispute. Both professionals testified in this trial that the case should not have been mediated due to domestic violence. They had found a pattern of 'coercive and controlling behaviour' by the father/ ex-husband. There had been no additional reports or case filings about domestic violence since the successful mediation. What had primarily changed was professional assessment given to the court. The judge's final ruling was to divide primary parenting according to the age and psychological alignment of children (towards one parent and alienated from the other). That is, the mother was awarded sole custody and primary placement with the two younger children and an older child who was allied with her, while the father was awarded sole custody and primary placement for an older son who was allied with him. How is the earlier mediation agreement now to be assessed? Was this a two-year failure because the parents should not have been expected to co-parent given domestic violence? Did a mediated agreement allow any temporary success?

ADR professionals may understandably use such case examples to debate the merits of mediation and how to assess when mediation is appropriate. Courts evaluate these cases within a larger concern of efficient (or at least lower cost) court settlement. For some parents, mediation is a welcomed intervention that provides rational answers to the chaos of co-parenting in the wake of a failed relationship. For others, mediation provides a means to continue conflict and rack up resentment. For many, mediation sessions become part of what can be a blur of court process, logistics and low- to high-level hostility between 'co-parents'. As a Child Enforcement Officer commented, parents under the stress of court hearings, 'Only hear something like the sound of the 
ocean in a seashell' and made a whooshing sound to illustrate. How can mediation be removed far enough from such stress to allow for greater parent empowerment and participation? What are realistic expectations?

An additional complication in programme evaluation is potential conflict between the court and parents given that both are responsible for child welfare. That is, the family court ideal both assumes responsibility for children and supports the authority of parents to assume that same responsibility. This allows much room for contest not only between parents but also in a triangulation of parents in conflict with court commissioners and judges. Mediation can end up placed in the middle of this triangle. One judge described mediation as a 'speed bump' used to slow down parents. A court commissioner described mediation as a 'pressure valve' that allows emotional venting. In a later conversation, the commissioner added that many parties still seek findings of fault, despite 'no fault' legal reform. Thus, mediation case referral is not only in the shadow of the law but also in the wake of a family court trying to send cases back to private ordering by parties through the mediation programme.

Contrast this context with the early days of family court mediation: Pilot court mediation studies were conducted at a time when all divorce cases could be randomly assigned to mediation. These samples must have included amicable parties who appreciated mediation as a way to avoid the adversarial fault finding that past divorce laws required (in order to grant divorce). These 'easy' cases can now be resolved privately, and should rarely reach court as a dispute. In comparison to pilot study samples, then, the available sample for mediation referral has changed. Today's sample is likely to have a lower proportion of essentially cooperative parties and a higher proportion of family court cases with high conflict. These high conflict cases may have one or two parties seeking third party resolution, a finding of fault, and/or a division of parenting responsibility. Such cases were randomly assigned to mediation in past pilot studies but are mandated to mediation today (unless there is a clear domestic violence or substance abuse problem). The meaning of mediation agreement and termination in today's context thus requires some reconsideration. Statistical comparison with agreement rates from past studies, when mediation was a new alternative, can distort as much as inform present knowledge.

\section{Conclusion}

As shown through the US family court mediation study, there can be mischief in relying on standard evaluation measures for understanding how mediation works in practice. Focus on initial agreement may best reflect the interests of courts in settlement and the professional interests of mediators interested in their agreement rate track record. It may not always represent how mediation transformed or was transformed by parties at the time of mediation and afterwards. This mischief has been raised in previous studies and scholarship as proof that mediation does not always work as intended, and as an argument that mediation is an ideology pushed by ADR proponents (Harrington and Merry 1988; Nader 1993). In my research, I have not resolved claims over the meanings of mediated agreement among professionals as much as focused on asking whether professional frames used to evaluate mediation are similar to or different from those of disputants. And, in comparing professional and disputant evaluations of mediation, I examine how the meanings of mediation for disputants can change over time, such as through court decisions and private parenting or family events.

My goal is better dialogue and collaboration between researchers and practitioners. This article began with the metaphor of Ahuy: da repatriation to illustrate how standardisation may be a necessary component and yet also become problematic when followed too rigidly. This can result in a museum model of mediation, carefully preserved through professional training and programme policy. The dangers of standardisation can be compared with the mischief caused by the Ahuy: da when they are kept too far from fields of practice and/or preserved too well as professional and scientific objects. The Ahuy: da cannot be owned by any individual (or organisation), and work best when repatriated to the landscapes where they belong. They achieve success through decomposition, and restore balance through engagement and deterioration. Researchers can capture 
such decomposition and engagement by conducting small scale, qualitative studies. There is much to be gained in learning how our models may not only work as expected but may also transform or be transformed in unintended ways. As seen in the family court mediation study, museum models however well perfected are simply not as useful when they fail to capture the experiences of those who are not ADR experts but are rather those we intend to help through ADR as intervention. Ethnographic research is one way to learn with those engaged in ADR in all of its messiness. This approach allows repatriation of knowledge for research and practice.

\section{About the author}

Alexandra Crampton is an associate professor in the Department of Social and Cultural Sciences at Marquette University in Milwaukee, Wisconsin. She received a Master's in social work and a joint PhD (anthropology and social work) from the University of Michigan. Past mediation experience mainly includes landlord/tenant and adult guardianship disputes. Her ongoing mediation research and practice interest is in elder and family court mediation. She would like to thank Marquette University's Office of Sponsored Research Programs and Center for Peacemaking for grants funding research presented in this article.

\section{References}

Adams, W. (1998) The Philosophical Roots of Anthropology. Stanford, CA: CSLI Publications.

Alfini, J., Barkai, J., Bush, R. Hermann, M., Hyman, J. Kovach, K., Liebman, C., Press, S. and L. Riskin. (1994) What happens when mediation is institutionalised? Ohio State Journal on Dispute Resolution 9: 307-32.

Amato, P., Kane,]. and Spencer, James. (20n) Reconsidering the 'good divorce'. Family Relations 60: 5n-24. https://doi.org/ro.nn/j.1741-3729.2on.00666.x

Ballard, R., Holtzworth-Munroe, A., Applegate, A. and D'Onofrio, B. (2011) Factors affecting the outcome of divorce and paternity mediations. Family Court Review 49(1): 16-33. https://doi.org/ro.1n1/j.17441617.2oro.013 50.x

Bernard, H.R. (2002) Research Methods in Anthropology: Qualitative and Quantitative Methods. Thousand Oaks, CA: Sage.

Burawoy, M. (2003) Revisits: an outline of a theory of reflexive ethnography. American Sociological Review 68(5): 64 5-79. Retrieved from http://www.jstor.org/stable/r519757

Cohen, J. (2006) Intentional conversations about the globalization of ADR. Hamline Journal of Public Law and Policy 27: 217-27.

Coy, P. G. and Hedeen, T. (2005) A stage model of social movement co-optation: community mediation in the United States. The Sociological Quarterly 46(3): 40 5-3 5. https://doi.org/ro.1111/j.15 3 3-8 525 .2005.00020.x

Crampton, A. (2006) Fall 2005 Dispute Resolution Symposium: addressing questions of culture and power in the globalization of ADR: lessons from African influence on American mediation. Hamline Journal of Public Law and Policy 27(2): 229-41.

Crampton, A. (2015) Ethnographic refusal as research method. Qualitative Social Work 14(4): 453470.

Dingwall, R. (2oro) Divorce mediation: should we change our mind? Journal of Social Welfare and Family Law 32(2): ro7-17. https://doi.org/ro.ro80/09649069. 2010. 506307

Dingwall, R. and Kidd, K. (2003). After the fall ... : capitulating to the routine in professional work. Penn State Law Review 108: 67-89.

Emery, R. (2012) Renegotiating Family Relationships: Divorce, Child Custody, and Mediation (2 ${ }^{\text {nd }}$ edn). New York: Guilford Press.

Ferguson, T. ] ., Anyon, R. and Ladd, E. J. (2000) Repatriation at the Pueblo of Ziini: diverse solutions to complex problems. In D. A. Mihesua (ed.) Repatriation Reader: Who Owns American Indian Remains? 282-91. Omaha, NE: University of Nebraska Press.

Fineman, M. (1991) The Illusion of Equality: The Rhetoric and Reality of Divorce Reform. Chicago, IL: University of Chicago Press. 
Greatbatch and Dingwall, R. (1999) The marginalization of domestic violence in divorce mediation. International Journal of Law, Policy and the Family 13(2): 174-90. https://doi.org/10.1093/lawfam/13.2.174

Grillo, T. (1991) The mediation alternative: process dangers for women. The Yale Law Journal 100(6): 1545-1610. https://doi.org/ro.2307/796781

Harrington, C. B. and Merry, S. E. (1988) Ideological production: the making of community mediation. Law and Society Review 22(4): 709-35. https://doi.org/ 10.2307/3053707

Johnson, J. (2001) Contaminated collections: preservation, access, and use. In Proceedings of a Symposium Held at the National Conservation Training Center (NCTC) Shepherdstown, West Virginia April 6-9, 2001. Retrieved on 2 November 2017 from www.spnhc.org/media/assets/cofo 2001 V17N12.pdf.

Mayer, B. (2013) Mediation: 50 years of creative conflict. Family Court Review 51(1): 34-41. https://doi.org/10.1111/fcre.12005

McAdoo, B. and N. A. Welsh. (2004) Look before you leap and keep on looking: lessons from the institutionalization of court-connected mediation. Nevada Law Journal 5: 399-432.

Merenstein, A. (1992) The Zũni quest for repatriation of the war gods: an alternative basis for claim. American Indian Law Review 71(2): 589-637. https://doi.org/10.23ozhoo6256z

Merry, S. (1990) Getting Justice and Getting Even: Legal Consciousness among Working-Class Americans. Chicago, IL: University of Chicago Press.

Mnookin, R. H. and Kornhauser, L. (1979) Bargaining in the shadow of the law: the case of divorce. The Yale Law Journal 88(5): 950-97. https://doi.org/10.2307/115. тм

Moloney, L., Qu, L., Weston, R. and Hand, K. (2013) Evaluating the work of Australia's family relationship centres: evidence from the first 5 years. Family Court Review 51(2): 234-49. https://doi.org/10.1111/fcre.12023

Murphy, J. and Singer, J. (2015) Divorced from Reality: Rethinking Family Dispute Resolution. New York: New York University Press.

Nader, L. (1993) Controlling processes in the practice of law: hierarchy and pacification in the movement to reform dispute ideology. Ohio State Journal on Dispute Resolution 9: 1-25.

Parkinson, P. (2014) The payoffs and pitfalls of laws that encourage shared parenting: lessons learned from the Australian experience. Dalhousie Law Journal 3 7: 301-43.

Patton, B. (1984) On Teaching Negotiation. Program on Negotiation working paper. Cambridge, MA: Harvard Law School.

Press, S. (2013) Family court services: a reflection on 50 years of contributions. Family Court Review 51(1): 4855. https://doi.org/10.1111/fcre.12007

Redmond, B. (2004) Reflection in Action: Developing Reflective Practice in Health and Social Services. Farnham: Ashgate Publishing.

Salem, P. ( 2009) The emergence of triage in family court services: the beginning of the end for mandatory mediation? Family Court Review 47(3): 371-88. https://doi.org/IO. I I I 1/j. 1744-16 I 7.2009.01262.X

Saposnek, D. (2004) Commentary: The future of the history of family mediation research. Conflict Resolution Quarterly 22(1-2): 37-53. https://doi.org/10.1002/lliLil

Schneider, A. K. (2012) Foreword: the future of court ADR: mediation and beyond. Marquette Law Review 95(3): 12-27. https://doi.org/10.1016/B978-o-12-804oz4-4.00015-z

Schon, D. (1983) The Reflective Practitioner: How Professionals Think in Action. New York: Basic Books.

Silbey, S. (1993) Mediation mythology. Negotiation Journal 9(4): 349-53 . https://doi.org/10.1111/j.15719979.1993.tboon2.x

Simpson, B. (1998) Changing Families. Oxford: Berg Books.

Singer, J. (2008) Dispute resolution and the post-divorce family: implications of a paradigm shift. Family Court Review 47(3): 363-70.

Staller, K. (2006) Railroads, runaways, and researchers: returning evidence rhetoric to its practice base. Qualitative Inquiry 12(3): 503-22. https://doi.org/rn.n77/ 1077800406286524

Stokoe, E. (20n) Simulated interaction and communication skills training: the 'conversation-analytic role-play method'. In C. Antaki (ed.) Applied Conversation Analysis n9-39. Basingstoke: Palgrave Macmillan. 
Suro, R. (1990) is' effort to regain idols may alter views of Indian art. New York Times (I3 August): Al, Al3.

Trinder, L. and Kellett, J. (2007) Fairness, efficiency and effectiveness in court-based dispute resolution schemes in England. International Journal of Law, Policy and the Family 21(3): 323-40. https://doi.org/rn.rn93/lawfam/ebmoo9

Welsh, N. A. (20n) Current transitional state of court-connected ADR. Marquette Law Review 95(3): 873-86. 